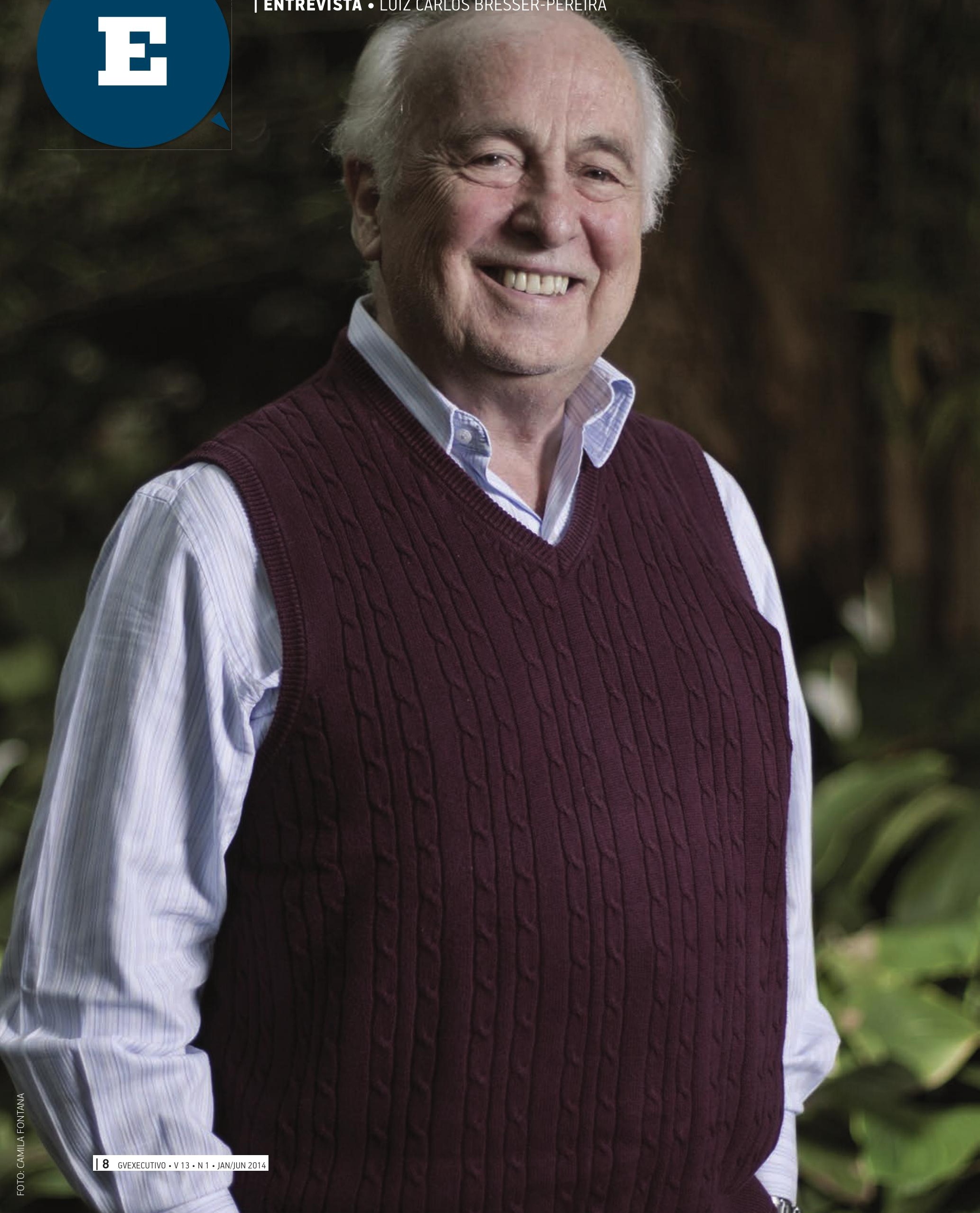




\section{NOVO DESENVOLVIMENTISMO: UM POSSÍVEL CAMINHO PARA O BRASIL}

| POR ALINE LILIAN DOS SANTOS + EDUARDO HENRIQUE DINIZ + MARIA IRENE STOCCO BETIOL

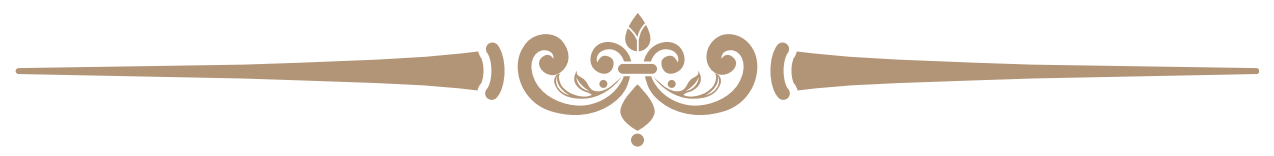

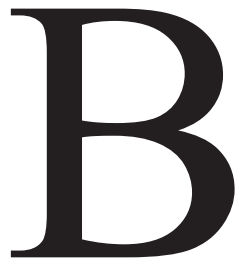

acharel em Direito, economista, político, professor, escritor, administrador do setor público e privado. Poucos possuem tantas habilidades e um currículo amplo como o de Luiz Carlos Bresser-Pereira.

Entre as funções que acumulou durante a carreira, foi Ministro da Fazenda (1987) em meio à crise inflacionária provocada pelo fracasso do Plano Cruzado durante o governo de José Sarney. Também atuou como Ministro da Administração e Reforma do Estado (1995-1998) e Ministro da Ciência e Tecnologia (1999) ao longo dos dois mandatos de Fernando Henrique Cardoso. Ainda na administração pública, foi presidente do Banco do Estado de São Paulo (BANESPA) e Secretário de Governo em 1983 durante a gestão de André Franco Montoro. Além disso, ajudou a fundar o Partido da Social Democracia Brasileira (PSDB), mas desligou-se em 2011 afirmando que o partido deixou de ser de centro-esquerda.
No setor privado, foi vice-presidente do grupo Pão de Açúcar entre 1963 e 1982.

Professor Emérito da FGV, Bresser participou da consolidação da Escola de Administração de Empresas de São Paulo (EAESP) desde o fim dos anos 1950, tendo forte influência na instauração do departamento de Economia e programas como o de graduação em Administração Pública, curso referência oferecido pela Escola.

Hoje, ele se dedica inteiramente à vida acadêmica e propõe o novo desenvolvimentismo como modelo para o Brasil, visando promover o crescimento econômico por meio da poupança interna - evitando o endividamento externo e reforçando o nacionalismo - , do déficit público zero, da taxa de câmbio competitiva e equilibrada e da menor taxa de juros, promovendo o aumento dos investimentos e o desenvolvimento industrial.

Em entrevista exclusiva à GV-executivo, Bresser conta sua trajetória na FGV-EAESP, revela detalhes sobre a história da Escola e fala sobre o que o Brasil precisa para se desenvolver e ocupar um lugar de destaque no cenário mundial. ๑ 
GV-executivo: Quando jovem, você queria ser juiz. $\mathrm{O}$ que o fez mudar de ideia e como surgiu o interesse por Economia?

Bresser: Na época, tudo me levou a cursar Direito. Inclusive, meu pai era advogado.

Quando estava no terceiro ano da faculdade, li o Cadernos de Nosso Tempo, revista publicada pelo Instituto Superior de Estudos Brasileiros (ISEB) e que possuía uma interpretação nacionalista e desenvolvimentista do Brasil. Fiquei absolutamente fascinado e declarei que não seria mais juiz, mas economista ou sociólogo do desenvolvimento.

Finalizei o curso de Direito, mas nunca atuei na área. Dos 16 aos 22 anos trabalhei em jornal, mas tinha um salário muito baixo. Então, apareceu uma oportunidade na área de publicidade, na qual atuei por algum tempo, mas sempre com a ideia fixa de ser economista ou sociólogo do desenvolvimento.

GV-executivo: Como começou sua história na vida acadêmica?

Bresser: Fiz um concurso e entrei na EAESP em 1959. A oportunidade surgiu por meio do meu irmão, que era aluno da $2^{\mathrm{a}}$ turma de graduação. Foi a forma que encontrei de trilhar meu caminho na vida acadêmica.

$\mathrm{Na}$ época, os professores fundadores da EAESP ficavam um ano no Brasil para dar assessoria e aprender com os docentes da Missão Americana, depois passavam um ano e meio na Michigan State University, nos Estados Unidos. Lá estudei o mínimo de Administração de Empresas e o máximo de Sociologia e Economia.

Quando voltei ao Brasil, por volta de 1962, eu tinha um projeto de

\section{NUNCA FUI INTELECTUAL PARA DESCOBRIR A VERDADE ETERNA, DESCUBRO AS MINHAS VERDADES PARA DEBATÊ-LAS E FAZER COM QUE AS COISAS MELHOREM. VEJO ISSO COMO UMA INTERVENÇ̃̃O NA POLITTICA}

pesquisa sobre as origens étnicas e sociais dos empresários paulistas e participei de uma conferência internacional da UNESCO, onde pedi para o Delfim Netto ser meu orientador. Ele aceitou e, em 1972, terminei o doutorado em Economia na Faculdade de Economia, Administração e Contabilidade da Universidade de São Paulo (FEA/ USP).

GV-executivo: A EAESP nasceu a partir dos esforços de várias entidades, entre elas, a FGV e a Michigan State University (EUA), que ministrou aulas e ofereceu sugestões acadêmicas e educacionais para a Escola, o que ficou conhecido como Missão Americana. Qual foi a sua relação com ela?

Bresser: Tive uma boa participação. Foi quando aprendi o conceito de líder, o qual levo para toda a vida: "Líder é aquele que tem os meios para atender às necessidades dos seus liderados".

Minha última boa experiência na Missão foi quando voltei ao Brasil e aceitei dar dois cursos: o de Introdução à Administração, na graduação, e o de Diretrizes Administrativas, na pós-graduação. Cinco anos depois, saí do departamento de Administração Geral e entrei no de Ciências Sociais, mas já com a ideia de ser economista. Anos depois, criamos o departamento de Economia.
GV-executivo: Quantos departamentos existiam na Escola nessa época?

Bresser: Quando entrei, tinha o de Administração Geral e Pessoal, de Marketing, de Finanças, de Produção e de Ciências Sociais. Tempos depois, separou-se o de Produção, Métodos Quantitativos, Ciências Sociais, Economia e, mais recentemente, o de Gestão Pública.

GV-executivo: Como se deu a criação do curso de pós-graduação na EAESP?

Bresser: Por volta de 1962/1963, não havia propriamente uma pós-graduação, mas uma tentativa, a ideia de instituí-la. Convoquei uma reunião e propus uma reforma. A ideia foi, em princípio, aprovada, e elegeu-se o Gustavo de Sá e Silva como coordenador do Curso de Pós-Graduação (CPG) - já que ele era mais sênior - e eu como vice.

De 1964 até 1971, fui o coordenador do programa. Durante os dois primeiros anos, as aulas eram de dia e, nos últimos dois anos e meio, à noite.

Em 1965, transformei aquele curso em mestrado. Para fazer o mestrado, era preciso realizar três disciplinas adicionais e apresentar uma tese. Por volta de 1968, ampliei o curso diurno para tempo integral e inseri aulas de manhã e à tarde, impedindo o aluno de trabalhar. O CPG era um sucesso, porque não tinha tese. $\mathrm{O}$ que eu estava instituindo era o mestrado profissional, um MBA americano. 


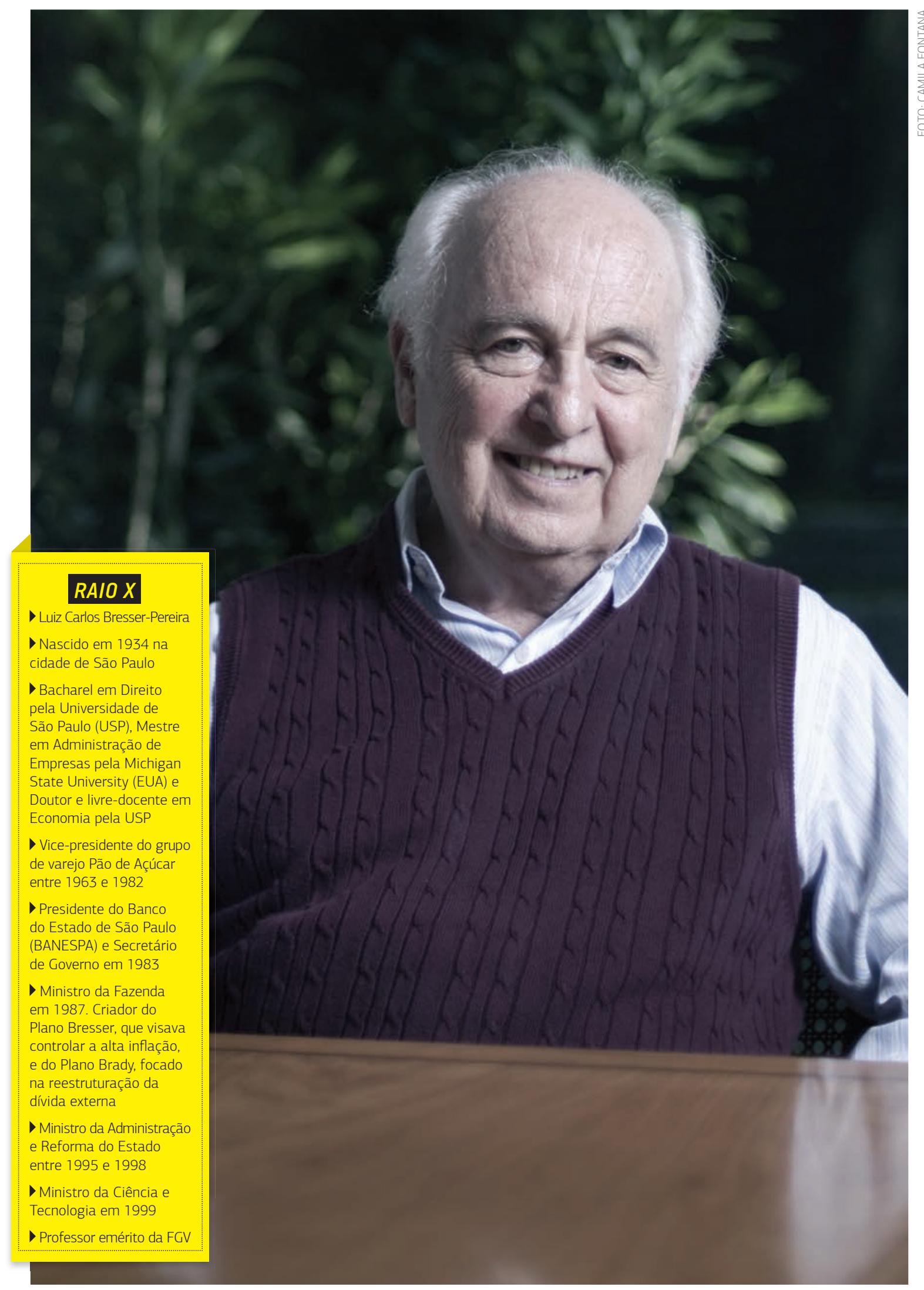



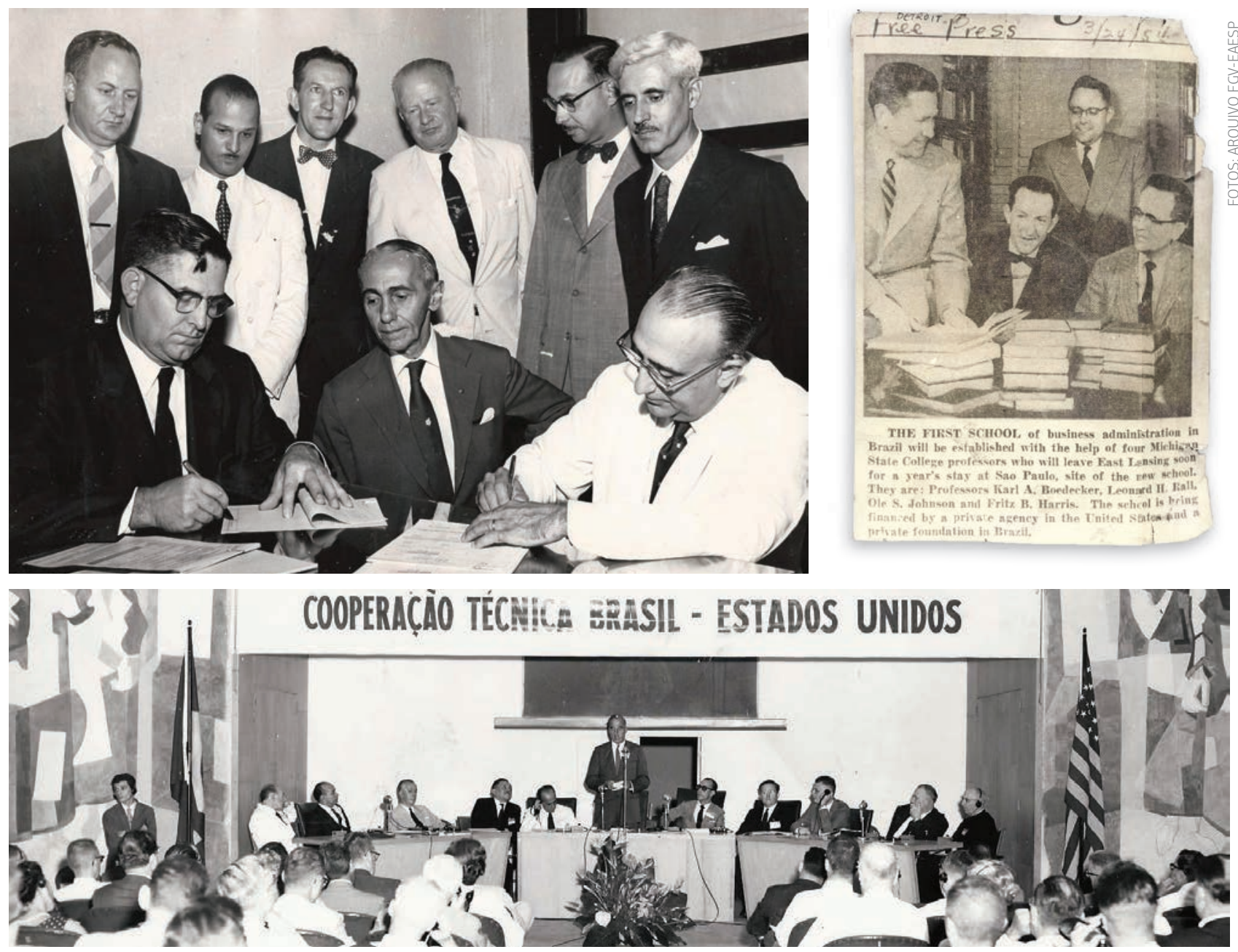

Imagens da Missão Americana: acordo entre a FGV e a Michigan State University (EUA) para a instauração da EAESP

Poderia ser um grande programa, mas, em 1970, o governo federal regulamentou os cursos de pós-graduação no Brasil. Eles pensavam que mestrado deveria ser acadêmico, uma etapa para o doutorado. A minha pós-graduação com e sem dissertação, com e sem título de Mestre - mas com o título de CPG -, era pautada nos grandes MBAs americanos, que são profissionais, não acadêmicos.

Foi a minha grande derrota na Escola, porque resisti à mudança, mas não adiantou. Em 1971, foi feita a reforma. O CPG diurno - que também era um mestrado — transformou-se no mestrado acadêmico, e o noturno, tornou-se o Curso de Especialização em Administração para Graduados (CEAG).

GV-executivo: O programa de graduação em Administração Pública da EAESP é referência no Brasil. De onde veio a ideia de instituí-lo?

Bresser: Em 1970, o presidente da Fundação, Luís Simões Lopes, criou o curso de graduação em Administração Pública por meio de um acordo com o estado de São Paulo, no qual este forneceria recursos e o programa seria oferecido gratuitamente aos alunos.

O curso iniciou com grande interesse e entusiasmo. Durante um tempo, teve alunos muito bons, pois era gratuito e a concorrência era maior do que no programa de Administração de Empresas. Em 1995, o subsídio acabou e ele passou a ser pago.

$\mathrm{Na}$ realidade, não tínhamos um verdadeiro curso de graduação em Administração Pública. Quando o presidente da Fundação, Carlos Ivan, criou o departamento de Gestão Pública, o GEP, não sabíamos se era possível instaurar um curso autônomo nesse segmento, se teríamos alunos o suficiente. Então, perguntei em uma reunião: "Por que não criamos coragem e instituímos a graduação em Administração Pública?”. Fizemos e foi um sucesso. 


\section{O PSDB FOI MUITO BOM NA PARTE SOCIAL, MAS NÃO HOUVE INTERESSE PELO PROBLEMA NACIONAL. NẤO ERA UM GOVERNO QUE DEFENDIA O NACIONALISMO ECONOOMICO OU DESENVOLVIMENTISTA}

GV-executivo: Além de professor, você também atuou como administrador de empresas. Como surgiu essa oportunidade?

Bresser: Meu irmão era colega do Abilio Diniz. Eles me convidaram para fazer a propaganda da loja 2 do Pão de Açúcar. Fiz a 2, a 3, a 4 e, em 1963, eles me chamaram para ser diretor da rede. Eu disse que só poderia ser por meio período, pois o outro era para a EASP. Foi uma briga de 20 anos com o Abilio. Ele concordou, mas nunca se conformou.

GV-executivo: Você já declarou que nunca sonhou em ser político, apenas aceitou convites e propostas. Como aconteceu sua entrada no mundo da política?

Bresser: Dirigia uma empresa de imenso sucesso (Pão de Açúcar). Associado ao Abilio, construímos um império empresarial.

Apesar disso, continuava com a vida acadêmica. Também era um intelectual público. Nunca fui intelectual para descobrir a verdade eterna, descubro as minhas verdades para debatê-las e fazer com que as coisas melhorem. Entendo isso como uma intervenção na política.

Em 1982, Franco Montoro foi eleito governador de São Paulo e me convidou para fazer parte do grupo de economistas do seu plano de governo. Logo depois, ele me chamou para ser o presidente do BANESPA, que foi meu primeiro cargo público, em 1983, onde fiquei por 2 anos. Franco também me convidou para ser chefe da Casa Civil e foi nessa hora que tive de decidir se queria ou não ser político. Decidi que não. Passaram-se os anos, eu não queria, mas acabei sendo Ministro da Fazenda.

Quando saí do Ministério da Fazenda, resolvi os problemas da crise familiar no Pão de Açúcar e ajudei na crise financeira do grupo. Combinei que, quando solucionasse essas pendências, eu sairia. Foi aí que o Mário Covas me chamou para ser candidato a Deputado Federal. Então, fiquei tentado.

Em 1993, perguntei para minha família e amigos se deveria aceitar a proposta. Eu tinha recurso para financiar a campanha, apoio e um nome razoavelmente conhecido e respeitado. Decidi apenas quando um amigo e um genro me disseram: "Você pode contribuir mais para o país sendo um intelectual do que sendo um deputado". Aí encerrei o assunto.

Logo depois disso, o Fernando Henrique me convidou para ser tesoureiro da sua campanha. Sou muito seu amigo e achei que ele faria um governo de esquerda. Foi quando propus a reforma gerencial do Estado. Saí em 1999 e, há 13 anos, não faço outra coisa senão ser um acadêmico, um intelectual público.
GV-executivo: Você é um dos fundadores do PSDB e, recentemente, desvinculou-se do partido alegando que não se identificava mais com a sua proposta. Por quê?

Bresser: Saí por um motivo muito simples. Sou um social-democrata e um nacionalista econômico que defende um grau moderado de intervenção do Estado na economia. Como? Coordenando os setores não competitivos da economia, deixando o competitivo inteiramente por conta do mercado e fazendo uma política macroeconômica ativa. Isso é o desenvolvimentismo.

Não quero fazer a revolução socialista, mas não quero simplesmente um Estado liberal. Quero um Estado social-democrata, que tenha serviços universais de educação, saúde, assistência e previdência sociais etc. Toda a lógica da minha reforma gerencial foi em torno dessa ideia.

Mas aconteceu o que eu temia. Quando assinei o livro da fundação do PSDB, em 1988, não me apeguei ao problema do desenvolvimentismo. Eu dizia: "Ótimo, ganhamos!", mas pensava: "Como aconteceu em outros países, é provável que o partido socialista - que se diz revolucionário — vire social-democrata quando chegar ao poder e empurre o partido que se diz social-democrata para a direita”. Foi exatamente o que ocorreu. 


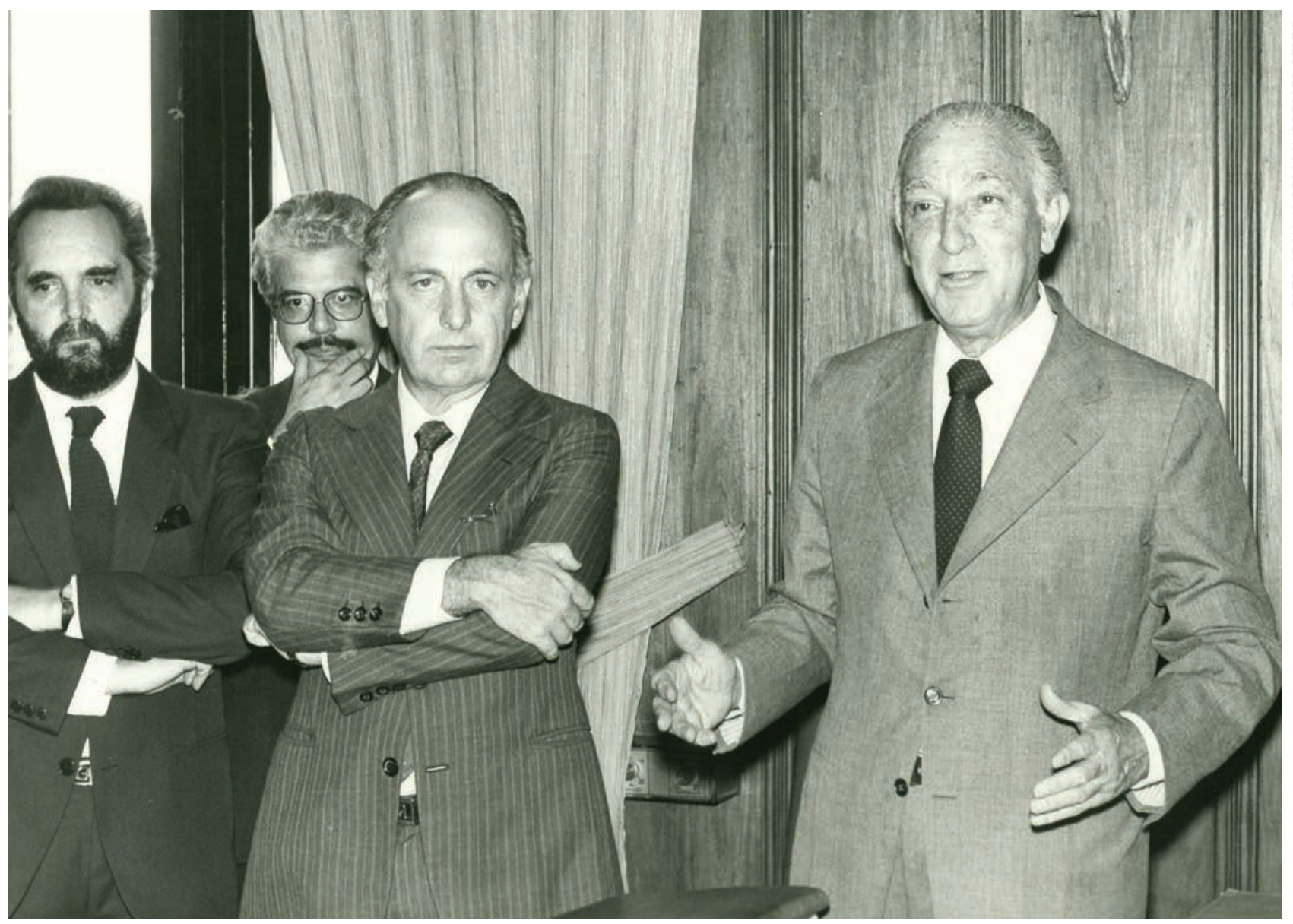

Bresser-Pereira como Secretário de Governo no mandato de André Franco Montoro (1983)

O PSDB tem gente muito boa, mas hoje é um partido de centro-direita. Isso se percebeu especialmente na política econômica do governo, porque na parte social (educação, saúde etc.) foi muito eficaz. Também não houve interesse pelo problema nacional. Não era um governo que defendia o nacionalismo econômico ou desenvolvimentista.

Tive uma influência marxista e keynesiana. Sou keynesiano, mas muito heterodoxo. O governo Fernando Henrique não tinha nada disso, houve até uma política quase que agressiva no sentido oposto. Por exemplo, tirar da Constituição a preferência de empresas nacionais comprarem as estatais - coisa que todos os países fazem. Quer privatizar, tudo bem, mas quando se trata de privatização de empresas estatais monopolistas, não dá para permitir que os espanhóis subsidiem suas empresas para comprarem as nossas.

GV-executivo: Nos últimos anos, o Brasil foi descrito como o país do futuro, mas essa visão vem mudando. Será que se gerou uma expectativa muito grande em relação ao país? Como é possível a 7a maior economia do mundo ter quadros tão alarmantes de pobreza e desigualdade?
Bresser: Quando saí do governo, fui para Oxford e escrevi um paper em que critiquei não só os 20 anos de economia brasileira, mas a América Latina inteira. Quatro anos depois, fiz outro artigo em que analisava a política econômica do governo Fernando Henrique.

Para entender melhor, a teoria da dependência foi criada pelo notável marxista André Gunder Frank, em 1965, em um ensaio no qual ele expõe a ideia de uma revolução burguesa, capitalista, por meio da associação dos empresários industriais com a burocracia pública e os trabalhadores. Isso nunca ocorreu nos países em desenvolvimento, que são dependentes. 
O BRASIL PRECISA TER UMA TAXA DE CÂMBIO QUE POSSIBILITE O EQUILÍBRIO INDUSTRIAL, TORNANDO COMPETITIVAS AS EMPRESAS E INDÚSTRIAS NACIONAIS

As ideias da dependência haviam se espalhado por toda a América Latina. Foi aí que, em 1966, Fernando Henrique foi para o Chile, juntou-se a Enzo Faletto, um sociólogo de esquerda, e escreveu o que é o seu grande livro: Desenvolvimento e dependência na América Latina, em que aceitam a tese da inexistência de uma burguesia nacional. Essa interpretação foi chamada de teoria da dependência associada.

Então, existia a teoria da dependência radical (ou da superexploração imperialista), do pessoal mais à esquerda, que, diante da situação, propunha a revolução socialista (André Gunder Frank, Ruy Mauro Marini, Theotonio dos Santos e Florestan Fernandes), e a teoria da dependência associada, dominante na América Latina, a qual dizia que já que não era possível ter uma burguesia nacional, a solução era se associar ao império (Estados Unidos) e aproveitar as frestas. As multinacionais seriam responsáveis pelo desenvolvimento e o crescimento se daria por meio da poupança externa.

Eu pensava que a interpretação do Fernando Henrique fosse igual à minha, mas não era. Aprendi que a versão associada pregava a não existência de uma burguesia nacional - coisa com a qual nunca concordei, pois acho que a nossa burguesia é ambígua e contraditória; em alguns momentos é nacionalista, em outros se entrega às elites centrais.

Aí entendi que o Fernando Henrique foi coerente em suas posições, mas evidentemente havia uma grande distância em relação às minhas. Eu continuava acreditando que a burguesia brasileira é nacional dependente. Ela vive a contradição, a ambiguidade, alguns momentos pra lá, outros pra cá. Mas não é simplesmente dependente, é nacional.

Então, propus o novo desenvolvimentismo como alternativa ao velho desenvolvimentismo e à ortodoxia liberal ou convencional. Explicava que existia uma alternativa macroeconômica viável e muito melhor. Ao mesmo tempo, desenvolvi modelos econômicos, como o de crítica ao crescimento com poupança externa, o da doença holandesa etc., todos envolvendo a tendência à sobreapreciação cíclica e crônica da taxa de câmbio nos países em desenvolvimento.

Resolvi aplicar isso ao Brasil e escrevi o livro Macroeconomia da Estagnação (2007). Acontece que, em 2006, a economia brasileira voltou a crescer com força e, quando saiu o meu livro dizendo que estávamos fazendo uma macroeconomia da quase estagnação, parecia que minhas teorias estavam furadas. Mas parece que não é bem assim. Aquelas taxas de crescimento decorreram de um grande aumento dos preços das commodities e de o Lula aumentar o mercado interno por meio da distribuição de renda, especialmente com o salário mínimo e o Bolsa Família, que foi bemsucedido. As empresas industriais se beneficiaram de uma valorização cambial brutal e isso facilitava ao Lula aumentar salários e combater a inflação.

Assim, amigos — velhos desenvolvimentistas - me disseram: "Está vendo? Essa política desenvolveu o mercado interno". Uma tolice imensa. Acontece que, devido à apreciação cambial, aquele mercado interno ia ser capturado, como foi, pela importação. Porque quando se tratava de importar commodities, melhorou o preço, mudou o câmbio e tornou-se lucrativo importar aço, petróleo, trigo. Você importa de acordo com as padronizações mundiais. Com manufaturados não é assim. Exige marca, conhecimento, via de distribuição etc. Então, demora, em média, três anos.

Deu para o Lula terminar o governo dele gloriosamente, mas a herança para a Dilma foi pesada, já que ela pegou uma taxa de câmbio altamente apreciada. Tinha que depreciá-la, mas não podia, não tinha coragem nem sustentação social para fazê-lo. Quase voltamos à estagnação e eu estava absolutamente certo. 


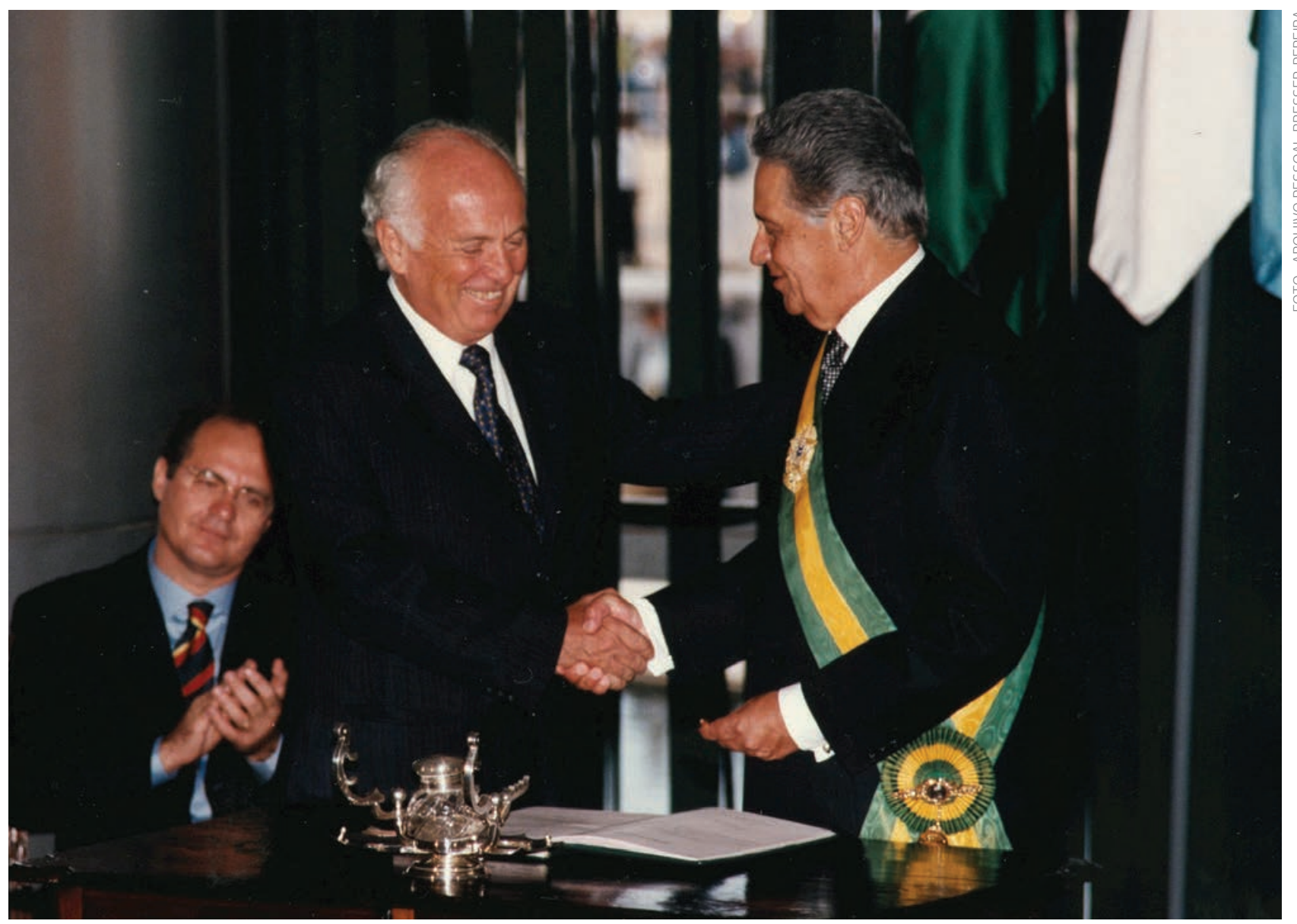

Bresser-Pereira com Fernando Henrique Cardoso durante o primeiro mandato do ex-presidente (1995-1998)

GV-executivo: Em sua opinião, qual seria o melhor caminho para o Brasil voltar a crescer?

Bresser: Dizem: "Tudo o que o Bresser fala é taxa de câmbio". Dos cinco preços macroeconômicos - a taxa de câmbio, a de juros, a de lucro, a de inflação e a de salários - , o mais estratégico e importante é a taxa de lucro. Sem ela, não tem capitalismo, não tem investimento. Entretanto, a que provoca alterações mais violentas de um dia para o outro é a taxa de câmbio, por isso, os economistas têm horror dela.

Nesses anos, consegui desenvolver um conjunto de modelos que constituem o que chamo de macroeconomia desenvolvimentista, ou macroeconomia estruturalista do desenvolvimento, e estou elaborando uma teoria da taxa de câmbio, pois descobri o seu valor.

GV-executivo: Mas, politicamente, isso não é complicado de ser implementado?

Bresser: Isso está muito claro para mim. O Brasil precisa ter uma taxa de câmbio que possibilite o equilíbrio industrial, ou seja, que torne competitivas as empresas e indústrias brasileiras que usam tecnologia no estado-da-arte mundial. Eu dizia que um bom valor era $\mathrm{R} \$ 2,90, \mathrm{R} \$ 3,00$ por dólar, mas um dos autores com quem estou escrevendo o livro Developmental Macroeconomics fez um estudo e chegou à conclusão de que o valor ideal é $\mathrm{R} \$ 3,30$.

Quando estávamos com o dólar a $\mathrm{R} \$ 2,20$, parecia uma loucura falar em R\$2,90. Então, se o Brasil quer crescer como no passado, ele precisa voltar a ter uma taxa de câmbio próxima a $\mathrm{R} \$ 3,30$, devido à oferta e procura de moeda.

Para isso, é preciso fazer uma desvalorização, o que é complicado, pois tem um custo, traz inflação, diminui salários e quebra empresas endividadas em dólar, isto é, três problemas incômodos. Por isso que, geralmente, desvalorizações são feitas em crises; depois você segura.

O Lula não segurou o câmbio, que seguiu valorizando. Insisti muito. O Palocci 


\section{HÁ UM GRANDE NÚMERO DE POLÍTICOS CORRUPTOS, MAS NÃO É A MAIORIA. NÂO EXISTE DEMOCRACIA SEM POLITTICA, ELAE A FORMA MAIOR DE BUSCAR NOSSOS OBJETIVOS DE LIBERDADE, BEM-ESTAR E JUSTIÇA}

jurou, por meio do Abilio Diniz, que quando a taxa de câmbio chegasse em $\mathrm{R} \$ 3,00$, não abaixava mais. Que nada!

É preciso uma discussão séria entre os economistas. Cheguei à conclusão de que tanto os desenvolvimentistas quanto os liberais - os primeiros defendem certo grau de intervenção do Estado e, os outros, o mínimo possível — revelam uma alta preferência pelo consumo imediato. Poderíamos chamar isso de populismo. Você vê os ortodoxos criticando o governo, mas ninguém fala da taxa de câmbio; vê os desenvolvimentistas dizendo: "A taxa de câmbio está boa, vamos fazer política industrial”. Bobagem!

GV-executivo: Você cita a China como exemplo de nacionalismo econômico e desenvolvimentista com alto nível de crescimento. Em sua opinião, é possível seguirmos por essa linha?

Bresser: O Brasil deixou de ser desenvolvimentista em 1991, no governo Collor, quando, além da abertura comercial, tivemos a abertura financeira. O Brasil nunca mais cresceu como antes. Entre 1950 e 1980, o país crescia a 4,1\% ao ano. Hoje, esse número está um pouco acima de $1 \%$.

Economias desenvolvimentistas são a China, o Vietnã, a Coreia - já quase rica -, a Índia. Países que já fizeram sua revolução capitalista. Países da América Latina, como o México e o Brasil, fizeram sua revolução desenvolvimentista entre 1930 e 1980 , mas depois a abandonaram. Temos o México - que não é mais uma nação, é uma dependência dos Estados Unidos - e o Brasil, que está mais para perto do México do que da China ou da Índia. Pelo menos, conservamos um pouco da nossa autonomia e não estamos nas mãos dos americanos.

Um nacionalista é aquele que pensa com a própria cabeça, de acordo com os interesses da sua nação. Um colonialista é o que pensa com a cabeça dos mais ricos e acha que os interesses dos poderosos são iguais aos nossos. Não são. "Nacionalismo" e "desenvolvimentismo" eram palavras feias nos 30 anos neoliberais do capitalismo, que acabaram em 2008, em uma crise tão importante como a de 1929.

GV-executivo: Para você, qual o potencial das manifestações promoverem transformações efetivas no Brasil?

Bresser: A mais importante transformação no país foi a democracia. Isso mudou o Brasil. Essas manifestações foram comparadas às de maio de 1968 (na França), às do Egito e da Tunísia, que eram sérias, queriam mudar o governo, o mundo. As nossas não. Foi um movimento contra algo específico, o aumento das passagens, e que pegou. Pegou porque houve uma campanha muito violenta contra a política no país nesses últimos 10 anos.
GV-executivo: Quando falamos em política no Brasil, geralmente ela está associada a um discurso pessimista, principalmente devido à corrupção. $\mathrm{O}$ que deve ser feito para isso mudar?

Bresser: Há um número relativamente grande de políticos corruptos, mas não é a maioria. Não existe democracia sem política, ela é nossa forma maior de participar da vida pública e buscar nossos objetivos de liberdade, bem-estar e justiça.

Como se pode desmoralizar os políticos desse jeito? O julgamento do mensalão foi lamentável. José Dirceu, um político competente e com grande espírito público, cometeu um crime e precisava ser punido, mas com muito menos espetáculo e severidade. Há políticos e empresários que ficam milionários nesse meio, envolvendo valores infinitamente maiores, e com esses... nada.

GV-executivo: Qual conselho você daria a quem pretende seguir carreira na Administração Pública?

Bresser: Sejam republicanos. Sejam capazes de distinguir o interesse pessoal do nacional e defendê-lo, mesmo que seja contra o seu próprio interesse. Isso é ser republicano.

ALINE LILIAN DOS SANTOS > Jornalista da GV-executivo > aline.lilian@fgv.br

EDUARDO HENRIQUE DINIZ > Editor chefe da GV-executivo > eduardo.diniz@fgv.br

MARIA IRENE STOCCO BETIOL > Editora convidada da GV-executivo > misbetiol@gmail.com 